\title{
Use of tranexamic acid in craniosynostosis surgery
}

\author{
Justin P Martin MD¹, Jessica S Wang BS², Kasandra R Hanna MDํ, Madeline M Stovall BS², Kant Y Lin MD
}

JP Martin, JS Wang, KR Hanna, MM Stovall, KY Lin. Use of tranexamic acid in craniosynostosis surgery. Plast Surg 2015;23(4):247-251.

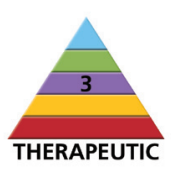

BACKGROUND: Intraoperative tranexamic acid (TXA) administration has been used to abate blood loss in a variety of surgical procedures. Several recent studies have supported its efficacy in reducing transfusion requirements in pediatric cranial vault reconstruction (CVR).

OBJECTIVE: To conduct a retrospective chart review to determine whether a significant reduction in packed red blood cell (PRBC) and fresh frozen plasma (FFP) transfusions exists when TXA is used.

METHODS: A retrospective cohort study of 28 patients who underwent CVR for sagittal craniosynostosis was performed. Transfusion requirements for 14 patients who did not receive TXA were compared with 14 patients who did. Predictors of increased blood product transfusion were also studied. RESULTS: Total volume of PRBC transfusion was reduced by $50 \%$ with the use of TXA $(\mathrm{P}=0.004)$ with a $34 \%$ reduction in intraoperative PRBC transfusion $(\mathrm{P}=0.017)$ and a $67 \%$ reduction in postoperative $\mathrm{PRBC}$ transfusion $(\mathrm{P}<0.001)$. Total volume of FFP transfusion was reduced by $46 \%$ $(\mathrm{P}=0.002)$ and postoperative FFP transfusion was reduced by $100 \%$ $(\mathrm{P}=0.001)$. The use of TXA was associated with a lower total volume of PRBC $(\mathrm{P}=0.003)$ and FFP $(\mathrm{P}=0.003)$ transfusions. Older patient age was associated with lower total volume of $P R B C$ transfused $(P=0.046$ and $\mathrm{P}=0.002)$, but not with FFP $(\mathrm{P}=0.183$ and $\mathrm{P}=0.099)$ transfusion volumes. Increasing patient weight was associated with lower $\mathrm{PRBC}(\mathrm{P}=0.010$ and $\mathrm{P}=0.020)$ and FFP $(\mathrm{P}=0.045$ and $\mathrm{P}=0.016)$ transfusion volumes.

CONCLUSION: TXA decreased blood product transfusion requirements in patients undergoing CVR for sagittal craniosynostosis, and should be a routine part of the strategy to reduce blood loss in these procedures.

Key Words: Blood loss; Blood transfusion; Cranial vault reconstruction; Craniosynostosis; Tranexamic acid

\section{L'utilisation d'acide tranexamique en cas de chirurgie de la craniosynostose}

HISTORIQUE : L'administration d'acide tranexamique (ATX) intraopératoire vise à limiter la perte de sang dans le cadre de diverses interventions chirurgicales. Plusieurs études récentes en appuient l'efficacité pour réduire les transfusions lors des reconstructions de la voûte crânienne (RVC) en pédiatrie.

OBJECTIF : Effectuer une analyse rétrospective des dossiers pour déterminer si l'utilisation d'ATX s'associe à une diminution importante des transfusions de culots globulaires (CG) et de plasma frais congelé (PFC). MÉTHODOLOGIE : Les chercheurs ont réalisé une étude rétrospective de cohorte auprès de 28 patients qui ont subi une RVC pour corriger une craniosystose sagittale. Ils ont comparé les transfusions chez 14 patients qui n'avaient pas reçu d'ATX à celles des 14 patients qui en avaient reçu. Ils ont également étudié les prédicteurs d'une transfusion accrue de produits sanguins.

RÉSULTATS : Le volume total de transfusion de CG diminuait de $50 \%$ grâce à l'utilisation d'ATX $(\mathrm{P}=0,004)$, y compris une réduction de $34 \%$ des transfusions de CG intraopératoire $(\mathrm{P}=0,017)$ et de $67 \%$ des transfusions de $C G$ postopératoire $(\mathrm{P}<0,001)$. Le volume total de transfusion de $\mathrm{PFC}$ intraopératoire diminuait de $46 \%(\mathrm{P}=0,002)$ et celui de transfusion postopératoire, de $100 \%(\mathrm{P}=0,001)$. L'utilisation d'ATX s'associait à une diminution du volume total de transfusions de $\mathrm{CG}(\mathrm{P}=0,003)$ et de $\mathrm{PFC}$ $(\mathrm{P}=0,003)$. Un âge plus avancé était lié à un volume total de $\mathrm{CG}$ transfusé plus faible $(\mathrm{P}=0,046$ et $\mathrm{P}=0,002)$, mais pas à celui de $\mathrm{PFC}(\mathrm{P}=0,183$ et $\mathrm{P}=0,099)$. Un poids plus élevé s'associait à un volume $\mathrm{CG}(\mathrm{P}=0,010$ et $\mathrm{P}=0,020)$ et de PFC $(\mathrm{P}=0,045$ et $\mathrm{P}=0,016)$ plus faible.

CONCLUSION : L'ATX réduisait le volume de transfusion de produits sanguins chez les patients subissant une RVC pour corriger une craniosynostose sagittale. Son utilisation devrait être systématique pour réduire la perte de sang lors de ces interventions.
Craniosynostosis is a condition defined by the premature closure of One or more cranial sutures, resulting in distorted skull expansion as the brain grows beneath. This condition occurs in approximately 0.6 per 1000 births (1). It has been theorized that craniosynostosis, especially if multisutural in nature, can lead to increased intracranial pressure (ICP) and impaired cerebral growth. This, in turn, could result in abnormalities of cognitive development if the process is left untreated (2). In an effort to avoid these undesirable consequences, craniosynostosis is usually corrected surgically within the first year of life (3). The standard procedure for this is performed through an open approach cranial vault reconstruction (CVR), which entails removal of the affected suture(s), and a significant portion of the misshaped cranial bones, followed by recontouring and rearrangement of the bones to create a more normal cranial vault volume and head shape $(4,5)$. Other technical variations for the correction of skull deformities associated with craniosynostosis have been described and are occasionally used, such as distraction osteogenesis (6) or a variation known as spring-mediated cranioplasty $(7,8)$. Finally, several minimally invasive techniques using multiple small scalp incisions (9) or endoscopic approaches (10-12) have also been advocated, but these techniques have not gained as much widespread acceptance as the open approach due to unproven results and decreased recent morbidity rates for the open approach compared with historical benchmarks (13).
Open cranial vault reconstruction is a substantial operation with many inherent risks, the most common and notable of which is the potential for large volume blood loss. Associated massive transfusions related to this blood loss may lead to many serious short- and longterm sequelae (14-16). Many strategies to curb blood loss and transfusion requirements have been developed and implemented (17). These techniques include normovolemic hemodilution (18), autologous preoperative blood donation (19), use of intraoperative autologous blood transfusion or the 'cell saver' device $(20,21)$, postoperative drain-reinfusion (22), erythropoietin (23), fibrin sealants (24), controlled hypotension (15), technical strategies such as the use of Raney clips, bone wax and injection of the scalp with an epinephrinecontaining anesthetic (25), and use of systemic antifibrinolytic agents such as tranexamic acid (TXA).

There have been several recent studies, including some prospective randomized trials, that support the effect of TXA on reduction of perioperative blood loss and transfusion requirements in CVR $(3,4,26$ 28). TXA is a synthetic derivative of lysine that exerts an antifibrinolytic effect via reversible blockage of lysine binding sites on plasminogen molecules, which inhibits the interaction of plasminogen and plasmin with lysine residues on the surface of fibrin, leading to an inability of plasmin to degrade fibrin. It is six to 10 times more potent in plasminogen/plasmin binding than $\varepsilon$-aminocaproic acid (Amicar,

${ }^{1}$ Department of Plastic Surgery, University of Virginia Health System; ${ }^{2}$ University of Virginia School of Medicine, Charlottesville, Virginia, USA

Correspondence: Dr Kant Y Lin, Department of Plastic Surgery, University of Virginia Health System, Box 800376, Charlottesville,

Virginia 22908, USA. Telephone 434-924-2528, fax 434-924-5801, e-mail kyl5s@virginia.edu 
TABLE 1

Demographic data and characteristics of sagittal cranial vault reconstruction patients

\begin{tabular}{lccc}
\hline & \multicolumn{2}{c}{ Group } & \\
\cline { 2 - 3 } Variable & TXA $(\mathbf{n}=\mathbf{1 4})$ & No TXA $(\mathbf{n}=14)$ & $\mathbf{P}$ \\
\hline Age, months & $10 \pm 9$ & $7 \pm 2$ & 0.305 \\
Weight, kg & $9.0 \pm 2.1$ & $7.9 \pm 1.8$ & 0.137 \\
Male/female ratio, $\mathrm{n}: \mathrm{n}$ & $12: 2$ & $13: 1$ & 0.541 \\
Duration of surgery, $\mathrm{h}$ & $3.8 \pm 0.6$ & $3.3 \pm 0.7$ & 0.070 \\
Length of hospitalization, days & $4 \pm 1$ & $4 \pm 1$ & 0.482
\end{tabular}

Data presented as mean $\pm S D$ unless otherwise indicated, with groups compared using the Student's t test. Male/female ratios between groups were compared using Pearson's $X^{2}$ test. TXA Tranexamic acid

(Xanodyne Pharmaceuticals Inc, USA), another antifibrinolytic agent. It has also been shown to be effective in reducing blood loss and transfusion requirements in a large number of other hemorrhagic conditions, such as gastrointestinal bleeding, menorrhagia, dental and oral surgery procedures, liver transplantation, cardiac surgery, orthopedic surgery and prostatic surgery, among others. It is generally well-tolerated, with minor orthostatic reactions, diarrhea and nausea being the most common side effects (29).

Since January of 2012, we have used intraoperative TXA infusion in all CVR procedures at the University of Virginia Hospital (Charlottesville, Virginia, USA) in an effort to reduce surgical blood loss and transfusion requirements. We hypothesized that the use of TXA would lead to a significant reduction in perioperative transfusion requirements related to CVR procedures. We performed a retrospective review of all CVR procedures for sagittal craniosynostosis during this period, and have compared them with an equivalent number of these procedures before the use of TXA at our institution, to determine whether there was a significant reduction in transfusion requirements for these patients.

\section{METHODS}

After obtaining approval from the Institutional Review Board for Health Sciences Research (University of Virginia Health System, Charlottesville, Virginia), the records of all patients who underwent CVR for sagittal craniosynostosis at the University of Virginia Hospital since the institution of the use of TXA for these procedures, from January 2012 through March 2014, were reviewed. The records for a matching number of consecutive patients that underwent CVR for sagittal craniosynostosis up until January 2012, before TXA was used for this indication at the authors' institution, were also analyzed as the comparison group. To maximize the uniformity of the included patients, only those who underwent CVR for correction of sagittal craniosynostosis using a standardized surgical technique were included. Any patient with a history of previous cranial vault procedure, an associated syndrome, or synostosis of any other cranial sutures was excluded from the analysis. All patients underwent surgery with the same neurosurgeon and craniofacial plastic surgeon, the senior author (KYL).

A total of 28 patients met the inclusion criteria, 14 in each of the pre-TXA and TXA groups, for the present study. Data collected from patient records included total volume in milliliters $(\mathrm{mL})$ of each type of blood product transfused both during surgery and postoperatively. To further standardize these values, each was divided by the respective patient weight in kilograms $(\mathrm{kg})$. Types of blood products transfused included packed red blood cells (PRBC) and fresh frozen plasma (FFP). The mean adjusted volume $(\mathrm{mL} / \mathrm{kg})$ of each product as well as age, weight, operative duration, hospital length of stay and male to female ratio was also determined for each group.

\section{Surgical technique}

All patients underwent CVR for sagittal craniosynostosis using a standardized surgical technique. Briefly, in this technique, the sagittal, bilateral coronal and bilateral lambdoid sutures are removed, and the
TABLE 2

Intra- and postoperative data regarding blood product transfusion requirements

\begin{tabular}{lccc}
\hline & \multicolumn{2}{c}{ Group } & \multirow{2}{*}{ Variable } \\
\cline { 2 - 3 } & TXA $(\mathbf{n = 1 4 )}$ & No TXA $(\mathbf{n}=14)$ & P \\
\hline FFP transfused, $\mathrm{mL} / \mathrm{kg}$ & $40.3 \pm 25.8$ & $51.4 \pm 29.7$ & 0.297 \\
$\quad$ Intraoperative & $0.0(0.0-25.5)$ & $34.7(0.0-87.3)$ & $0.001^{*}$ \\
Postoperative & $47.7 \pm 26.1$ & $88.2 \pm 36.3$ & $0.002^{*}$ \\
Total & & & \\
PRBC transfused, $\mathrm{mL} / \mathrm{kg}$ & $42.6(20.0-148.4)$ & $64.7(22.2-128.5)$ & $0.017^{*}$ \\
Intraoperative & $8.8 \pm 8.4$ & $26.9 \pm 13.9$ & $<0.001^{*}$ \\
Postoperative & $49.3(20.0-172.1)$ & $99.3(38.9-151.4)$ & $0.004^{*}$ \\
Total & &
\end{tabular}

Data presented as mean $\pm S D$, with groups compared using the Student's t test, or median (range) due to significant skewing, with groups compared using the nonparametric Mann-Whitney $U$ test. *Statistically significant. FFP Fresh frozen plasma; PRBC Packed red blood cells; TXA Tranexamic acid

parietal bones are outfractured to increase skull width. The fused sagittal suture is then used as a bone graft strut, fixed with absorbable plates and screws, to hold the biparietal bones apart to maintain the expanded skull width. The frontal bones are removed and contoured with a combination of Tessier bone benders and barrel stave osteotomies to remove any frontal bossing present. If indicated, the occipital bone is contoured with bone benders and barrel stave osteotomies as well. All bones are held in place with absorbable plates and screws. Infiltration of the scalp with an epinephrine-containing local anesthetic, use of Raney clips on the scalp edges, use of an ultrasonic scalpel blade to cut bone, and meticulous control of hemostasis during dissection with cautery and bone wax are employed to reduce blood loss.

\section{Intraoperative management}

TXA is administered intraoperatively by the anesthesiologists. This includes a $30 \mathrm{mg} / \mathrm{kg}$ loading dose after induction of general anesthesia and before the skin incision, followed by a continuous infusion at $10 \mathrm{mg} /$ $\mathrm{kg} / \mathrm{h}$ until skin closure is complete. Both PRBC and FFP are transfused intraoperatively. The transfusion criteria are based on one of two principles. Some anesthesiologists require signs of hemodynamic instability (ie, hypotension and/or tachycardia) to begin transfusion, and others begin transfusion prophylactically and titrate the transfusion rate based on hemodynamic parameters and laboratory values. In all cases, hemoglobin and hematocrit are monitored hourly with blood gasses, with respective transfusion goals of $100 \mathrm{~g} / \mathrm{L}$ and $30 \%$, respectively.

\section{Postoperative management}

All patients are admitted postoperatively to the pediatric intensive care unit under the care of the pediatric critical care and neurosurgery services. Postoperative transfusion parameters are based on hematocrit, platelet count and international normalized ratio, which are typically measured every $6 \mathrm{~h}$ for at least the first 12 postoperative hours, followed by every $8 \mathrm{~h}$ for the next $24 \mathrm{~h}$, and every $12 \mathrm{~h}$ to daily, or as necessary, for the remainder of the hospitalization. The transfusion thresholds for each are a hematocrit $<21 \%$, platelet count $<100 \times 10^{9} / \mathrm{L}$ and international normalized ratio $>1.4$. However, the overall condition of the patient is taken into consideration, and transfusion is often deferred, according to the judgment of the physician caring for the patient at the time, if one of these numbers is slightly aberrant and the patient is stable with no signs of continued blood loss.

\section{Statistical analysis}

Statistical analysis was performed using the SPSS version 21 (IBM Corporation, USA). Continuous data following a Gaussian distribution were expressed as mean \pm SD and compared between TXA and pre-TXA groups by the two-sample Student $t$ test. Continuous data 
TABLE 3

Predictors of blood product transfusion

\begin{tabular}{|c|c|c|c|c|}
\hline \multirow[b]{2}{*}{ Variable } & \multicolumn{2}{|c|}{ Total FFP transfused $(\mathrm{mL} / \mathrm{kg})$} & \multicolumn{2}{|c|}{ Total PRBC transfused (mL/kg) } \\
\hline & Pearson, $\mathrm{P}$ & Spearman; P & Pearson; $\mathrm{P}$ & Spearman; P \\
\hline Age, months & $r=-0.26,0.183$ & $\rho=-0.32 ; 0.099$ & $r=-0.38 ; 0.046^{*}$ & $\rho=-0.56 ; 0.002^{*}$ \\
\hline Duration of surgery, $\mathrm{h}$ & $r=0.10,0.626$ & $\rho=0.14 ; 0.483$ & $r=0.16 ; 0.427$ & $\rho=0.13 ; 0.523$ \\
\hline Length of hospitalization, days & $r=0.08,0.689$ & $\rho=0.10 ; 0.615$ & $r=0.02 ; 0.925$ & $\rho=0.15 ; 0.446$ \\
\hline
\end{tabular}

*Significant correlation based on the Pearson product-moment correlation and Spearman's rank-order correlation. FFP Fresh frozen plasma; PRBC Packed red blood cells

following a non-Gaussian distribution were reported as median (range) and compared using the Mann-Whitney U test. Categorical data, namely male/female ratios, were compared using the Pearson $\chi^{2}$ test. Pearson product-moment correlation and Spearman's rank-order correlation were conducted to determine the correlation of TXA and four other covariates (age, weight, duration of surgery and length of hospital stay) on total transfusion volumes of FFP and PRBC, to rule out any confounding possible relationships. Pearson correlation coefficient was not obtained for the TXA variable due to the noncontinuous nature of the data, and a Spearman correlation was performed instead. For all statistical analyses, a two-tailed $\mathrm{P}<0.05$ was considered to be statistically significant.

\section{RESULTS}

Twenty-eight infants who underwent a CVR for sagittal craniosynostosis were included in either the pre-TXA $(n=14)$ or the TXA $(n=14)$ group. There was no significant difference in age, weight, male to female ratio, duration of surgery or length of hospitalization between the two groups (Table 1).

Significant reductions in transfusion of PRBC and FFP with the use of TXA were demonstrated by the analysis (Table 2). Total volume of PRBC transfusion was reduced by $50 \%$ with the use of TXA $(\mathrm{P}=0.004)$ with a $34 \%$ reduction in intraoperative $\mathrm{PRBC}$ transfusion $(\mathrm{P}=0.017)$ and a $67 \%$ reduction in postoperative $\mathrm{PRBC}$ transfusion $(\mathrm{P}<0.001)$. Total volume of FFP transfusion was reduced by $46 \%$ $(\mathrm{P}=0.002)$ and postoperative FFP transfusion was reduced $100 \%$ to $0 \mathrm{~mL}$ transfused $(\mathrm{P}=0.001)$. The reduction in intraoperative FFP transfusion by $21 \%$ did not reach statistical significance $(\mathrm{P}=297)$.

Several predictors of blood product transfusion volume were found in the analysis (Table 3). As expected, based on the above described results, the use of TXA was significantly associated with a lower total volume of PRBC $(\mathrm{P}=0.003)$ and FFP $(\mathrm{P}=0.003)$ transfusions. Increasing patient age was significantly associated with lower total volume of $\mathrm{PRBC}$ transfused $(\mathrm{P}=0.046$ and $\mathrm{P}=0.002)$, but not with FFP $(P=0.183$ and $P=0.099)$ transfusion volumes. Increasing patient weight was significantly associated with lower $\mathrm{PRBC}$ $(\mathrm{P}=0.010$ and $\mathrm{P}=0.020)$ and FFP $(\mathrm{P}=0.045$ and $\mathrm{P}=0.016)$ transfusion volumes. There was no significant correlation between duration of surgery or length of hospitalization with transfusion volumes of either of the products.

\section{DISCUSSION}

The present retrospective cohort study demonstrated significantly decreased transfusion of PRBC and FFP when intraoperative infusion of TXA is administered in CVR for sagittal craniosynostosis.

Data analysis with Student's $t$ test and Mann-Whitney U test demonstrated a significant reduction in intraoperative PRBC transfusion $(\mathrm{mg} / \mathrm{kg})$ of $34 \%$ with intraoperative TXA administration. It also demonstrated a significant reduction of postoperative transfusion of PRBC and FFP by $67 \%$ and $100 \%$, respectively. A significant reduction in total (intraoperative and postoperative) transfusion of PRBC and FFP was also shown, with $50 \%$ and $46 \%$ reductions, respectively.

Our data analysis with Pearson product-moment correlation and Spearman's rank-order correlation showed intraoperative TXA infusion to be a significant predictor of reduced transfusion of PRBC and FFP. This also revealed greater patient age to be a predictor of decreased PRBC transfusion, and higher patient weight to be a predictor of reduced transfusion of PRBC and FFP. The correlation between greater relative volumes of blood product transfusion in smaller and younger infants could possibly be due to the disproportionate size of the head, which represents a greater percentage of total body surface area in these patients $(4,30)$. Also, smaller and younger infants are more likely to exxhibit greater hemodynamic instability, meeting criteria for transfusion. Duration of surgery and length of hospitalization were not found to be predictive of transfusion rates for either of the blood products included in the analysis.

We did not include surgical blood loss estimates in our analysis due to the inherent inaccuracies in how this is recorded (31), including sponge counts and measurements of operative suction volume in the setting of irrigation use. It is our belief that transfusion volumes served as a more precise and standardized indicator of surgical blood loss than actual blood loss estimates.

Although intravenous TXA has a relatively short half-life of approximately $2 \mathrm{~h}$ (32), we have included both intraoperative and postoperative transfusion volumes in our analysis. In most cases, blood loss stops by the end of the procedure. However, in light of intraoperative crystalloid administration and large postoperative fluid shifts, patients frequently require transfusion over the first several postoperative days to maintain a euvolemic state. The necessity of these postoperative transfusions was considered to be a direct result of surgical blood loss.

TXA is a relatively well-tolerated medication with infrequent side effects. Orthostatic reactions, diarrhea and nausea are the most commonly reported adverse events (29). Studies have shown that there is likely no increased risk of thrombogenicity associated with TXA (33). Hypersensitivity reactions have been documented but are infrequent (34). None of the patients in the present study experienced any of the adverse events associated with the use of TXA. Furthermore, the much more palpable risks of transfusion reaction or transmission of bloodborne diseases was in effect decreased due to the reduced amounts of blood products transfused in the patients that received TXA.

There are currently no standard guidelines on TXA administration for CVR procedures. Dadure et al (3) reported a $15 \mathrm{mg} / \mathrm{kg}$ loading dose followed by a $10 \mathrm{mg} / \mathrm{kg} / \mathrm{h}$ continuous infusion through skin closure, and Goobie et al (4) reported a $50 \mathrm{mg} / \mathrm{kg}$ loading dose followed by a $5 \mathrm{mg} / \mathrm{kg} / \mathrm{h}$ continuous infusion through skin closure. Our TXA administration protocol of a $30 \mathrm{mg} / \mathrm{kg}$ loading dose followed by a continuous infusion at $10 \mathrm{mg} / \mathrm{kg} / \mathrm{h}$ is similar to their protocols. Our results, and the results from those two studies, showed a significant reduction in PRBC transfusion requirements. Duran de la Fuente et al (27) used a protocol consisting of a $15 \mathrm{mg} / \mathrm{kg}$ loading dose and repeated $15 \mathrm{mg} / \mathrm{kg}$ boluses every $4 \mathrm{~h}$ throughout the procedure, followed by repeated $15 \mathrm{mg} / \mathrm{kg}$ boluses every $8 \mathrm{~h}$ for $48 \mathrm{~h}$ after skin closure. Their study showed a significant reduction in measured blood loss, but their reductions in transfusion volumes did not reach statistical significance. Based on these early results, it appears that a loading dose of $15 \mathrm{mg} / \mathrm{kg}$ to $50 \mathrm{mg} / \mathrm{kg}$ followed by an intraoperative infusion of $5 \mathrm{mg} / \mathrm{kg} / \mathrm{h}$ to $10 \mathrm{mg} / \mathrm{kg} / \mathrm{h}$ provides a significant hemostatic effect. 
Our findings are in agreement with other recent studies that showed reduced transfusion of PRBC and/or surgical blood loss with the use of TXA in CVR procedures $(3,4,26-28)$ but there are several notable differences between these studies and ours. Goobie et al (4), in a doubleblind, prospective study, demonstrated a $45 \%$ decrease in perioperative mean blood loss, a $41 \%$ decrease in perioperative mean PRBC transfusion volume, and a two-thirds reduction of perioperative exposure of patients to transfused PRBC with the use of TXA. All of these reductions reached statistical significance. However, there was no standardization of surgical technique among the patients included in the study (4).

Dadure et al (3), also in a double-blind, prospective study, showed an $85 \%$ reduction in the intraoperative volume of PRBC transfused and a total PRBC transfusion volume reduction of $57 \%$ with the use of TXA, and both of these reached statistical significance. However, all patients in this study were also pretreated with erythropoietin, for which the Food and Drug Administration issued a 'black box' warning in 2007 (35), and which adds a possible confounding factor to their statistical analysis.

A retrospective cohort study by Maugans et al (26), which investigated both minimally invasive and open surgery groups, showed lower blood loss and transfusion volumes in the open group when TXA was used, but neither difference was statistically significant. There was also no standardization of surgical technique in that study.

Estimation of blood loss, with its inherent inaccuracies, was a large part of all of these studies. Moreover, all of them investigated only PRBC transfusion rates, without accounting for any other types of blood products. Our study accounts for all products transfused, which included both PRBC and FFP.

Limitations of the present study include its small sample size and its retrospective design. Our small sample size excluded the possibility of

\section{REFERENCES}

1. Koh JL, Gries H. Perioperative management of pediatric patients with craniosynostosis. Anesthesiol Clin 2007; 25:465-81.

2. Garza RM, Khosla RK. Nonsyndromic craniosynostosis. Semin Plast Surg 2012;26:53-63.

3. Dadure C, Sauter M, Bringuier S, et al. Intraoperative tranexamic acid reduces blood transfusion in children undergoing craniosynostosis surgery: A randomized double-blind study. Anesthesiology 2011;114:856-61.

4. Goobie SM, Meier PM, Pereira LM. Efficacy of tranexamic acid in pediatric craniosynostosis surgery: A double-blind, placebo-controlled trial. Anesthesiology 2011;114;862-71.

5. Reiner D. Intracranial pressure in craniosynostosis: Pre- and postoperative recordings: Correlation with functional results. In: Persing JA, Edgerton MT, Jane JA, eds. Scientific Foundations and Surgical Treatment of Craniosynostosis. Baltimore: Williams \& Wilkins, 1989:263-9.

6. Akai T, Iizuka H, Kawakami S. Treatment of craniosynostosis by distraction osteogenesis. Pediatr Neurosurg 2006;42:288-92.

7. Lauritzen CG, Davis C, Ivarsson A, et al. The evolving role of springs in craniofacial surgery: The first 100 clinical cases. Plast Reconstr Surg 2008;121:545-54.

8. David LR, Proffer, P, Hurst WJ, et al. Spring-mediated cranial reshaping for craniosynostosis. J Craniofac Surg 2004;15:810-6.

9. Massimi L, Tamburrini G, Caldarelli M, et al. Effectiveness of a limited invasive scalp approach in the correction of sagittal craniosynostosis. Childs Nerv Syst 2007;23:1389-401.

10. Jimenez DF, Barone CM. Endoscopy-assisted wide-vertex craniectomy, "barrel-stave" osteotomies, and postoperative helmet molding therapy in the management of sagittal suture craniosynostosis. Neurosurg Focus 2000;9:e2.

11. Murad GJ, Clayman M, Seagle, MB, et al. Endoscopic-assisted repair of craniosynostosis. Neurosurg Focus 2005;19:e6.

12. Jimenez DF, Barone CM. Early treatment of anterior calvarial craniosynostosis using endoscopic-assisted minimally invasive techniques. Childs Nerv Syst 2007;23:1411-9.

13. Seruya M, Oh AK, Boyajian MJ, et al. Long-term outcomes of primary craniofacial reconstruction for craniosynostosis: A 12-year experience. Plast Reconstr Surg 2011;127:2397-406. controlling for age and weight as confounding variables with a logistic regression analysis, which would have been more ideal, to isolate any effect from TXA use. In any case, this observation can likely be explained by the fact that younger, smaller infants, with smaller blood volumes, are more likely to be hemodynamically unstable and, therefore, elicit product transfusion. Mean age and weight was the same between the TXA and non-TXA groups, which helps control for these variables. There is also a lack of dose-response data on TXA administration in infants. Therefore, the dose of TXA was administered based on the protocols described in the available literature. The use of transfusion volume as an indicator of blood loss also has potential inherent inaccuracies, due to variations in subjective transfusion thresholds used by anesthesia providers intraoperatively and physicians caring for the patients postoperatively (36). Despite this, we believe that transfusion volume is a more accurate indicator of blood loss than estimations of intraoperative blood loss. The present study was also only limited to CVR procedures for sagittal craniosynostosis, but was designed in this manner to standardize the patients as much as possible. Our results are likely applicable to a wide variety of cranial vault remodelling procedures performed for craniosynostosis.

The present study demonstrated that TXA significantly decreases the requirements for transfusion of PRBC and FFP in patients undergoing a standardized CVR for sagittal craniosynostosis. We believe that TXA administration should be a routine part of the strategy to reduce blood loss in these procedures.

DISCLOSURES: The authors have no financial disclosures or conflicts of interest to declare.

14. White N, Marcus R, Dover S. Predictors of blood loss in frontoorbital advancement and remodeling. J Craniofac Surg 2009;20:378-81.

15. Czerwinski M, Hopper RA, Gruss J, et al. Major morbidity and mortality rates in craniofacial surgery: An analysis of 8101 major procedures. Plast Reconstr Surg 2010;126:181-6.

16. Velardi F, Di Chirico A, Di Rocco C. Blood salvage in craniosynostosis surgery. Childs Nerv Syst 1999;15:695-710.

17. Di Rocco C, Tamburrini, Pietrini D. Blood sparing in craniosynostosis surgery. Semin Pediatr Neurol 2004;11:278-87.

18. Hans P, Collin V, Bonhomme V, et al. Evaluation of acute normovolemic hemodilution for surgical repair of craniosynostosis. J Neurosurg Anesthesiol 2000;12:33-6.

19. Longatti PL, Paccagnella F, Agostini S, et al. Autologous hemodonation in the corrective surgery of craniosynostosis. Childs Nerv Syst 1991;7:40-2.

20. Jimenez DF, Barone CM. Intraoperative autologous blood transfusion in the surgical correction of craniosynostosis. Neurosurgery 1995;37:1075-9.

21. Fearon JA. Reducing allogeneic blood transfusions during pediatric cranial vault surgical procedures: A prospective analysis of blood recycling. Plast Reconstr Surg 2004;113:1126-30.

22. Carless PA, Henry DA, Moxley JA, et al. Cell salvage for minimizing perioperative allogeneic blood transfusion. Cochrane Database Syst Rev 2010;CD001888.

23. Fearon JA, Weinthal J. The use of recombinant erythropoietin in the reduction of blood transfusion rates in craniosynostosis repair in infants and children. Plast Reconstr Surg 2002;109:2190-6.

24. Carless PA, Anthony DM, Henry DA. Systematic review of the use of fibrin sealant to minimize perioperative allogeneic blood transfusion. Br J Surg 2002;89:695-703.

25. Faberowski LW, Black S, Mickle JP. Blood loss and transfusion practice in the perioperative management of craniosynostosis repair. J Neurosurg Anesthesiol 1999;11:167-72.

26. Maugans TA, Martin D, Taylor J. Comparative analysis or tranexamic acid use in minimally invasive versus open craniosynostosis procedures. J Craniofac Surg 2011;22:1722-8. 
27. Duran de la Fuente P, Garcia-Fernandez J, Perez-Lopez C, et al. Usefulness of tranexamic acid in cranial remodeling surgery. Rev Esp Anestesiol Reanim 2003;50:388-94.

28. Song G, Yang P, Zhu S, et al. Tranexamic acid reducing blood transfusion in children undergoing craniosynostosis surgery. J Craniofac Surg 2013;24:299-303.

29. Dunn CJ, Goa KL. Tranexamic acid: A review of its use in surgery and other indications. Drugs 1999;57:1005-32.

30. Livingston EH, Lee S. Percentage of burned body surface area determination in obese and nonobese patients. J Surg Res 2000;91:2190-6.

31. van Uitert A, Megens JH, Breugem CC, et al. Factors influencing blood loss and allogeneic blood transfusion practice in craniosynostosis surgery. Pediatr Anesth 2011;21:1192-7.
32. FDA Drug Data: CYCLOKAPRON® tranexamic acid injection. 2011; < www.accessdata.fda.gov/drugsatfda_docs/label/2011/ 019281s030lbl.pdf.> (Accessed July 28, 2014).

33. Lindoff C, Rybo, G, Astedt B. Treatment with tranexamic acid during pregnancy and the risk of thromboembolic complications. Thromb Haemost 1993;70:238-40.

34. Imbesi S, Nettis E, Minciullo PL, et al. Hypersensitivity to tranexamic acid: A wide spectrum of adverse reactions. Pharm World Sci 2010;32:416-9.

35. Buemi M, Campo S, Cernaro V, et al. Erythropoietin and the truths of science. J Nephrol 2011;24:564-8.

36. Kearney RA, Rosales, JK, Howes WJ. Craniosynostosis: An assessment of blood loss and transfusion practices. Can J Anaesth 1989;36:473-7. 